\title{
Resumen
}

Se describe el reciente programa implementado en EEUU para la farmacovigilancia y el uso racional de isotretinoína con el objetivo de prevenir embarazos concomitantes a su uso y de evitar su administración en mujeres gestantes.

La isotretinoína es la configuración cis de la tretinoína (forma ácida del retinol). Esta indicada en pacientes de 12 años o mayores para el tratamiento del acné grave que no responde a otras terapias, incluidos los antibacterianos de acción sistémica. Tiene aplicaciones también en otros trastornos cutáneos como ser algunas formas de enfermedades neoplásicas. No está indicada para los casos de acné juvenil que no presentan complicaciones.

La dosis recomendada para el tratamiento del acné conglobado y nodular es de hasta $1 \mathrm{mg} / \mathrm{kg} / \mathrm{día}$, vía oral. Se administra junto con los alimentos, en una o dos tomas diarias. Si es necesario, se puede realizar un ajuste de la dosificación a las cuatro semanas de haber iniciado el tratamiento, en función de la respuesta y de los efectos secundarios.

El tratamiento puede durar entre 12 y 20 semanas, hasta que el recuento total de quistes haya descendido un $70 \%$ aproximadamente.

La mejoría puede continuar varios meses finalizada la administración del fármaco, siendo necesario esperar un mínimo dos meses antes de determinar si se requiere algún tipo de tratamiento posterior. La repetición del mismo no suele estar recomendada, sin embargo puede ser necesaria en algunos casos.

Si bien esta droga ha demostrado ser altamente eficaz para el tratamiento del acné, son numerosas las precauciones a tener en cuenta al momento de administrarla debido a sus potenciales efectos adversos.

El principal efecto adverso es la teratogénesis, por lo que su uso esta contraindicado en pacientes embarazadas, debiéndose evitar el embarazo no sólo durante el tratamiento sino hasta un mes luego de la finalización del mismo. Las malformaciones fetales asociadas a la isotretinoína incluyen: anomalías en el sistema nervioso central (hidrocefalia, malformaciones cerebelosas, microcefalia) rasgos dismórficos faciales, hendidura palatina, ausencia o malformaciones de la orejas, anomalías oculares (microftalmia) defectos cardíacos y anormalidades en las glándulas paratiroides y el tímo. En el Boletín Australiano de febrero de 2005 se informó que de 115 embarazos de pacientes que recibían el fármaco, el 18\% culminó en aborto espontáneo y el $23 \%$ fueron niños nacidos vivos pero con al menos una malformación. En el seguimiento de los niños expuestos al tratamiento durante la gestación se halló que cinco años después el $52 \%$ presentó algún grado de déficit intelectual.

Dada la incidencia de teratogénesis asociada al uso de isotretinoína y al fracaso de programas implementados anteriormente (SMART) la Adiministración de Alimentos y Drogas de EEUU (en inglés: FDA) aprobó en agosto de 2005 un Programa de Manejo Reforzado del Riesgo (Strengthened Risk Management Program) para este fármaco, con el objetivo de prevenir embarazos concomitantes a su uso y de evitar su administración a mujeres gestantes. Este programa llamado iPLEDGE entrará en vigencia a partir del 31 de diciembre de 2005. El mismo es un sistema electrónico que vincula, a través de un sitio web, a todos los involucrados en el proceso de medicación, desde el fabricante hasta el paciente.

Figura 1: Esquema del programa iPLEDGE

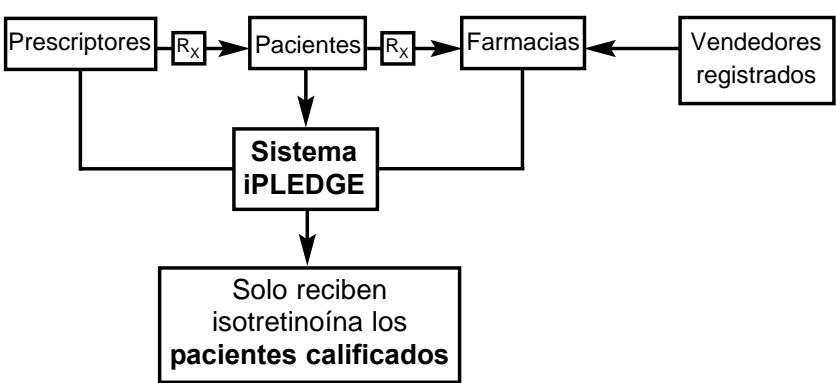

La isotretinoína sólo puede ser provista, prescripta y dispensada por profesionales registrados y "activados" previamente en el programa. Solo podrán recibirla y/o continuarla aquellos pacientes que reúnan todos los requisitos para ingresar al mismo.

El sistema iPLEDGE es capaz de rastrear y verificar elementos críticos controlando el acceso a la isotretinoína de la siguiente manera:

1- Activando el registro de los profesionales médicos y farmacéuticos participantes

2- Registrando a los pacientes participantes

3- Confirmando la visita mensual de los pacientes

4- Registrando mensualmente los resultados de las pruebas de embarazo y la información sobre anticoncepción que hayan recibido

5- Proveyendo materiales de educación para profesionales y pacientes.

El material educativo para profesionales provisto por el iPLEGDE consta de guías para: Buenas Prácticas para el uso de Isotretinoína, Consejo sobre Anticoncepción, para Reconocimiento de Desórdenes psiquiátricos en adolescentes y adultos jóvenes. Para acceder al programa se requerirá nombre de usuario y clave de acceso del profesional (médico o farmacéutico). Los requisitos para la incorporación y permanencia de los pacientes al Programa varían según el sexo y la edad del mismo. Entre los más relevantes se pueden mencionar:

- Conocimiento y aceptación de los términos del Programa.

- Uso de dos métodos anticonceptivos sugeridos (uno de ellos debe ser de barrera).

- Test de embarazo mensual.

Entrevista mensual para seguimiento y educación.

- Registro de eventuales efectos adversos.

Este programa, al ser de carácter obligatorio, posibilitaría monitorear "toda" la isotretinoína circulante. Si mediante el mismo no se lograra disminuir la incidencia de embarazos en pacientes en tratamiento, el próximo paso sería el retiro del fármaco del mercado. Si bien el iPLEDGE tiene como objetivo monitorear pacientes de sexo femenino con posibilidad de embarazarse, también se están tomando en cuenta otros efectos adversos referidos a la isotretinoína como: depresión, ideación suicida y comportamiento agresivo.

Consideramos que este sistema resultará sumamente beneficioso para la generación de información confiable que ayude tanto a pacientes como a profesionales a tomar decisiones evaluando los riesgos y beneficios del tratamiento y al mismo tiempo, realizar un monitoreo exhaustivo del fármaco a fin de actualizar constantemente la seguridad de su uso. ¿Podría llegar a ser posible la realización de un Programa similar en Argentina?

Gabriela Gonzalez Capdevila, Natalia Korzewycz, Roxana Beragua y Leonardo Garfi [ Farmacovigilancia Hospital Italiano de Buenos Aires. ]

\section{Bibliografía Recomendada}

Jick SS, Kremers HM, Vasilakis-Scaramozza C. Isotretinoin use and risk of depression, psychotic symptoms, suicide, and attempted suicide.Arch Dermatol. 2000 Oct:136(10):1231-6.

Martindale,Guía Completa de Consulta Farmacoterapéutica 1 Ed Pharma Editores 2003. 